\title{
A Case of Cortisol Producing Adrenal Adenoma Associated with a Latent Aldosteronoma: Usefulness of the ACTH Loading Test for the Detection of Covert Aldosteronism in Overt Cushing Syndrome
}

\author{
Daisuke Kukidome ${ }^{1}$, Nobuhiro Miyamura ${ }^{1}$, Kourin Sakakida ${ }^{1}$, Seiya Shimoda ${ }^{1}$, \\ Yoshinori Shigematu ${ }^{2}$, Kazuhiko Nishi ${ }^{3}$, Yasuyuki Yamashita ${ }^{2}$, Masatoshi Eto ${ }^{3}$, \\ Hironobu Sasano ${ }^{4}$ and Eiichi Araki ${ }^{1}$
}

\begin{abstract}
A 36-year-old woman with Cushing syndrome was evaluated for coexisting hyperaldosteronism, which was suggested by an abnormal response of the aldosterone-to-cortisol ratio in peripheral blood to the ACTHadministration despite a low basal aldosterone-to-renin ratio. Computed tomography revealed two independent tumors in the left adrenal gland, and adrenal venous sampling indicated hyperaldosteronism in addition to hypercortisolism in the same side. Postsurgical study including immunohistochemical analysis of steroidogenic enzymes suggested one adenoma to be cortisol-producing and the other, aldosterone-producing. The comorbidity of these different hormone-producing adenomas is not rare and careful pre-surgical evaluation is necessary to avoid post-surgical exacerbation of latent hyperaldosteronism.
\end{abstract}

Key words: Cushing syndrome with latent hyperaldosteronism, ACTH loading test

(Intern Med 51: 395-400, 2012)

(DOI: 10.2169/internalmedicine.51.5597)

\section{Introduction}

Once believed to be rare, primary aldosteronism (PA) is now known to be a more common disorder that represents the secondary hypertension (1-3). This epidemiological transition is a result of the advanced screening method using aldosterone-to-renin ratio (ARR) and the subsequent confirmatory tests, and also due to the detection of smaller aldosterone-producing adrenal adenoma (APA) and hyperplastic lesions of idiopathic hyperaldosteronism (IHA) that cannot be found by usual imaging tests, but which are found only by advanced technique of adrenal venous sampling (AVS). In addition, a radiologically detectable adrenal lesion in a PA patient may be a non-functioning adenoma or nodule combined with other occult APA(s) or IHA as previously reported (4). Therefore, when a surgical treatment is planned in a patient with PA, a definite localization of the responsible lesion(s) using AVS should be performed to avoid an erroneous adrenalectomy (5-7). In contrast, AVS is not recommended as a diagnostic procedure for adrenal Cushing syndrome (CS), because most of the cortisol-producing lesions are large enough to be identified by CT or MRI. In addition, an adrenal scintigram is effective to detect a definite uptake of iodine-adosterol into the lesion in CS patients, although it is not always effective in PA patients due to the generally smaller size of the aldosterone-producing lesion and a lower level of iodine-adosterol uptake compared with CS patients.

It is well known that the two disorders described above, PA and CS (including overt and subclinical), sometimes develop concomitantly, and a clinical guideline for the preoperative correct diagnosis of such cases has been proposed in

\footnotetext{
${ }^{1}$ Department of Metabolic Medicine, Kumamoto University School of Medicine, Japan, ${ }^{2}$ Department of Diagnostic Imaging, Faculty of Life Sciences, Kumamoto University, Japan, ${ }^{3}$ Department of Urology, Faculty of Life Sciences, Kumamoto University, Japan and ${ }^{4}$ Department of Pathology, Tohoku University School of Medicine, Japan

Received for publication April 3, 2011; Accepted for publication October 26, 2011

Correspondence to Dr. Eiichi Araki, earaki@gpo.kumamoto-u.ac.jp
} 
Table 1. Clinical Data on Admission

\begin{tabular}{|c|c|c|c|c|c|}
\hline Blood & & (normal range) & Urine & & (normal range) \\
\hline ACTH & $1.00 \mathrm{pg} / \mathrm{mL}$ & $(7.4-55.7)$ & U-free cortisol & $99.6 \mu \mathrm{g} /$ day & $(11.2-80.3)$ \\
\hline Cortisol & $17.5 \mu \mathrm{g} / \mathrm{dL}$ & $(6.5-25)$ & U-Aldosterone & $13 \mu \mathrm{g} /$ day & $<10 \mu \mathrm{g} /$ day \\
\hline DHEA-S & $36 \mu \mathrm{g} / \mathrm{dL}$ & $(23-266)$ & U-Ad & $18 \mu \mathrm{g} /$ day & $(1-11)$ \\
\hline Testosterone & $33.3 \mathrm{ng} / \mathrm{dL}$ & $(6-86)$ & U-MN & $0.02 \mathrm{mg} /$ day & $(0.04-0.19)$ \\
\hline PRA & $0.3 \mathrm{ng} / \mathrm{mL} / \mathrm{h}$ & $(0.3-5.4)$ & U-NMN & $0.02 \mathrm{mg} /$ day & $(0.09-0.33)$ \\
\hline PAC & $4.89 \mathrm{ng} / \mathrm{dL}$ & $(2.2-15)$ & VMA & $173 \mu \mathrm{g} /$ day & $(17.2-181.0)$ \\
\hline ARR & 16.3 & & & & \\
\hline P-Ad & $31 \mathrm{ng} / \mathrm{mL}$ & $(<100)$ & & & \\
\hline P-NAd & $129 \mathrm{ng} / \mathrm{mL}$ & $(100-450)$ & & & \\
\hline P-DO & $10 \mathrm{ng} / \mathrm{mL}$ & $(<20)$ & & & \\
\hline TSH & $0.77 \mu \mathrm{U} / \mathrm{mL}$ & $(0.5-5.0)$ & & & \\
\hline F-T3 & $2.91 \mathrm{pg} / \mathrm{mL}$ & $(2.3-4.0)$ & & & \\
\hline F-T4 & $1.61 \mathrm{ng} / \mathrm{dL}$ & $(0.9-1.7)$ & & & \\
\hline PRL & $7.4 \mathrm{ng} / \mathrm{mL}$ & & & & \\
\hline IRI & $8.5 \mu \mathrm{U} / \mathrm{mL}$ & & & & \\
\hline \multicolumn{6}{|c|}{$\begin{array}{l}\text { ACTH, adrenocorticotropic hormone; DHEA-S, dehydroepiandrosterone sulfate; PRA, } \\
\text { plasma renin activity; PAC, plasma aldosterone concentration; P-Ad, plasma adrenaline; P- } \\
\text { NAd, plasma noradrenaline; P-DO, plasma dopamine; TSH, thyroid-stimulating hormone; } \\
\text { FT3, free T3; FT4, free T4; PRL, prolactin; IRI, immunoreactive insulin; U-Ad, urinary } \\
\text { adrenaline; U-NAd, urinary noradrenaline; U-MN, urinary metanephrine; U-NMN, urinary } \\
\text { normetanephrine; VMA, vanillylmandelic acid. }\end{array}$} \\
\hline
\end{tabular}

a literature (8). However the literature did not clarify the differences between PA cases with subclinical CS (SCS) and those with overt CS, probably the former with detectable levels and the latter with undetectable levels of ACTH suppressed by autonomic secretion of cortisol. This case report demonstrates the usefulness of the ACTH loading test and subsequent AVS for the correct diagnosis of covert hyperaldosteronism in patients with overt CS. The patient initially presented with typical CS, and was finally found to have two separate adrenal adenomas. The post operative histopathological analysis indicated that one of them was a cortisolproducing adenoma (CPA) and the other an APA.

\section{Case Report}

A 36-year-old woman was referred to our hospital under the suspicion of CS. She had suffered from schizophrenia since the age of 19 years old, and had also developed hypertension, hyperlipidemia and glucose intolerance at the age of 31. Although medication with amlodipine besylate $(5 \mathrm{mg} /$ day), valsartan (160 mg/day), carvedilol (20 mg/day) and simvastatin $(10 \mathrm{mg} /$ day $)$ had been continued thereafter, control of hypertension and hyperlipidemia had remained insufficient (blood pressure was 140/90-172/118 mmHg, LDLcholesterol was $142 \mathrm{mg} / \mathrm{dL}$ ). A few months before referral to our hospital, an examination of her right hypochondrial pain by CT scan identified a gallstone, as well as a tumor of the left adrenal gland.

On admission, she was obese (body weight: $75.0 \mathrm{~kg}$, BMI: 31.6) and hypertensive (176/128 mmHg). Physical examination revealed moon face and central obesity, although purple striae of abdominal skin were absent. Other routine examinations showed no abnormality. An examination protocol for hypercortisolemic patients in our institution was undertaken. The levels of ACTH concentration and plasma rennin activity (PRA) were low, PAC was within normal range, PAC to PRA rate (ARR) was also within normal range, and urinary excretions of both free cortisol and aldosterone were slightly elevated (Table 1). Impaired glucose tolerance was present on the basis of the $75 \mathrm{~g}$ oral glucose tolerance test (Table 2a). There was neither circadian variation in serum cortisol nor suppression of serum cortisol by 1 and $8 \mathrm{mg}$ of dexamethasone administration (Table $2 \mathrm{~b}, \mathrm{c}$ ). These results were consistent with CS. Three examinations were performed according to the guideline proposed by the Japanese Endocrine Society (JES) for PA diagnosis (9). First, PAC was completely suppressed in a saline-loading test (Table 2e), secondly ARR was suppressed to 1.56 in a captopril challenge test (Table 2f), and lastly PRA was elevated from 0.5 to $2.5 \mathrm{ng} / \mathrm{mL} / \mathrm{h}$ in a furosemide-upright position challenge test (Table 2g). These results did not meet the JES guideline to confirm the interim diagnosis of PA. However, re-evaluation using thin slice $\mathrm{CT}$ revealed a small mass sized $1.0 \mathrm{~cm}$ in diameter in addition to the pre-recognized mass with $3.0 \mathrm{~cm}$ in diameter in left adrenal gland (Fig. 1a). Adrenal scintigraphy with ${ }^{131} \mathrm{I}-6-\beta$-iodomethylnorcholesterol showed a significant uptake by the left adrenal gland (Fig. 1b). Lastly, ACTH loading test $(0.25 \mathrm{mg}$ of cortro$\operatorname{syn}^{\circledR}$ ) was performed, in which the peak value of PAC to cortisol ratio was 1.19 (Table 2d). Since this value was regarded to indicate a high possibility of PA complication in the patient (8), AVS was performed.

Upon AVS, the levels of cortisol and PAC after ACTH loading were $969 \mu \mathrm{g} / \mathrm{dL}$ and $4,140 \mathrm{ng} / \mathrm{dL}$, respectively in the 
Table 2. Endocrinological Examinations

\begin{tabular}{|c|c|c|c|c|}
\hline \multicolumn{5}{|l|}{ a) $75 \mathrm{gOGTT}$} \\
\hline Time (min) & $\mathbf{0}$ & 30 & 60 & 120 \\
\hline Glucose (mg/dL) & 119 & 226 & 285 & 169 \\
\hline IRI $(\mu \mathrm{U} / \mathrm{mL})$ & 15.9 & 26.9 & 51.5 & 59.2 \\
\hline \multicolumn{5}{|c|}{ b) Circadian rhythm of cortisol and $\mathrm{ACTH}$} \\
\hline Time (h) & 7:30 & $14: 00$ & 17:00 & 23:00 \\
\hline Cortisol ( $\mu \mathrm{g} / \mathrm{dL})$ & 17.5 & 15.7 & 16.3 & 16.3 \\
\hline ACTH $(p g / m L)$ & 1.0 & 1.0 & 1.0 & 1.0 \\
\hline \multicolumn{5}{|c|}{ c) 1-mg or 8-mg overnight dexamethasone suppression test } \\
\hline & $\operatorname{ACTH}(\mathrm{pg} / \mathrm{mL})$ & & Cortisol $(\mu \mathrm{g} / \mathrm{dL})$ & \\
\hline 1-mg DST & 1.0 & & 18.4 & \\
\hline 8-mg DST & 1.0 & & 20.1 & \\
\hline \multicolumn{5}{|l|}{ d) ACTH administration test } \\
\hline Time (min) & $\mathbf{0}$ & 30 & 60 & \\
\hline PAC (ng/dL) & 10.6 & 36.8 & 33.0 & \\
\hline Cortisol $(\mu \mathrm{g} / \mathrm{dL})$ & 19.1 & 30.8 & 37.7 & \\
\hline PAC / Cortisol & & 1.19 & 0.88 & \\
\hline \multicolumn{5}{|l|}{ e) Saline-loading test } \\
\hline Time (hr) & $\mathbf{0}$ & 4 & & \\
\hline PRA (ng/mL/hr) & 0.7 & 0.5 & & \\
\hline PAC (ng/dL) & 3.27 & 2.30 & & \\
\hline \multicolumn{5}{|l|}{ f) Captopril challenge test } \\
\hline Time (min) & $\mathbf{0}$ & 90 & & \\
\hline PRA (ng/mL/hr) & 0.3 & 0.8 & & \\
\hline PAC (ng/dL) & 4.89 & 1.25 & & \\
\hline ARR & 16.3 & 1.56 & & \\
\hline \multicolumn{5}{|c|}{ g) Furosemide-upright position challenge test } \\
\hline Time (min) & $\mathbf{0}$ & 120 & & \\
\hline PRA (ng/mL/hr) & 0.5 & 2.5 & & \\
\hline PAC (ng/dL) & 4.74 & 33.72 & & \\
\hline
\end{tabular}

left adrenal vein (Table 3). The corresponding values in the right adrenal vein were $71 \mu \mathrm{g} / \mathrm{dL}$ and $1,123 \mathrm{ng} / \mathrm{dL}$, respectively. We postulated that the left adrenal gland was producing not only cortisol but also aldosterone because the PAC value in left adrenal vein was greater than 1,400 ng/dL, which met the criteria for PA of the JES guideline (9). The results of adrenal venous sampling strongly suggested hyperaldosteronism in addition to hypercortisolism in the left adrenal gland. Therefore, laparoscopic left adrenalectomy was performed.

After surgery, serum cortisol level decreased immediately to $0.4 \mu \mathrm{g} / \mathrm{dL}$ and hydrocortisone replacement $(15 \mathrm{mg} /$ day $)$ was continued. Eight months after surgery, her blood pressure was 142/82 mmHg under administration of nifedipineretard (40 mg/day), PAC was $2.54 \mathrm{ng} / \mathrm{dL}$ and PRA was 0.6 $\mathrm{ng} / \mathrm{mL} / \mathrm{h}$. The Cushingoid features disappeared, and the abnormality of lipid metabolism improved, such that no medication was necessary. These data suggested that the remaining right adrenal gland had normal function.

Macroscopic examination of the resected specimens revealed the presence of two different cortical lesions. Both of them were diagnosed as adrenocortical adenoma. The one measuring $25 \mathrm{~mm}$ in greatest dimension was admixed with tumor cells with clear cytoplasm $(60 \%)$ and those with eosinophilic cytoplasm (40\%) (Fig. 2a). Immunohistochemical analysis of steroidogenic enzymes demonstrated relatively abundant presence of both $17 \alpha$-hydroxylase (P450c 17) and 3-beta-hydroxysteroid dehydrogenase (3BHSD) immunoreactivity in this tumor (Fig. 2d, g). The other adrenocortical adenoma measuring $12 \mathrm{~mm}$ in greatest dimension was predominantly composed of tumor cells with abundant clear cytoplasm, and immunoreactivity of 3BHSD but not of P450c17 was detected in the tumor cells (Fig. 2c, f, i). Attached non-neoplastic adrenal gland was markedly atrophic with little DHEAST immunoreactivity in the zonae fasciculate and reticularis, and "paradoxical hyperplasia of the zona glomerulosa" $(10,11)$ with scarce 3BHSD immunoreactivity was also detected (Fig. 2b, e, h). All of these findings indicated that the large tumor was a CPA according to the expression of $\mathrm{c} 17$ and histological features, and the other tumor could represent an APA according to the absence of c17 and light microscopic findings. 

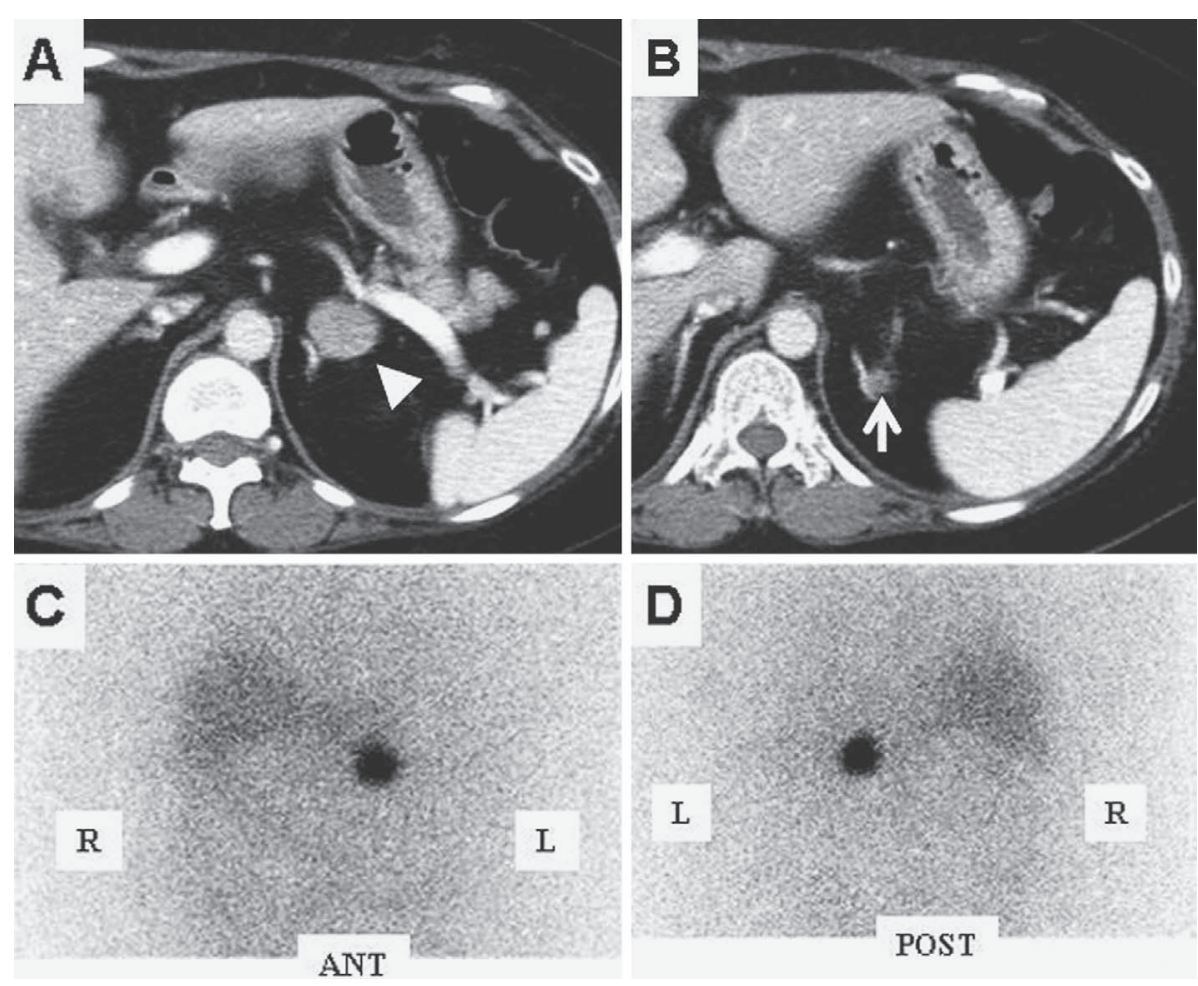

Figure 1. Adrenal dynamic CT and ${ }^{131} \mathrm{I}$-Adosterol scintigram without dexamethasone suppression: Adrenal CT showed (A) the left bigger adrenal adenoma (arrow head) and (B) the smaller adrenal adenoma (arrow). Adrenal scintigraphy with ${ }^{131}$ I-6- $\beta$-iodomethylnorcholesterol showed $(C, D)$ significant uptake by the left adrenal.

\section{Discussion}

A relatively high prevalence of concomitant PA and CS (including overt and subclinical) has recently been shown (8). Aldosterone- and cortisol-co-secreting adrenal tumors are now also of interest as a subtype of PA (12). Cardiovascular complications may be more severe in such cases (13). Most of the reported cases of the comorbidity can generally be classified into three groups. They comprise (i) both aldosterone and cortisol being simultaneously produced from a single, sometimes multiple, adrenocortical adenoma (A/CPA), (14-20) (ii) aldosterone produced from APA and cortisol from CPA, and these adenomas may exist unilaterally or separately in each other side, (21-27) (iii) aldosterone from both adrenal glands with bilateral hyperplasia (IHA) and cortisol from CPA $(28,29)$.

Clinical and pathological features of PA associated with SCS have recently been described (30). Most of these cases were analyzed in those primarily diagnosed as PA and afterward as complicated with SCS, with average values of aldosterone to cortisol ratio after ACTH stimulation of 2.4 and 1.2 in patients with simple-PA and PA/SCS, respectively (30). Aldosterone to cortisol ratio after ACTH stimulation in patients with simple-CPA (mean value: approximately 0.5 ) was significantly lower than that in those with CPA/PA (mean value: approximately 1.3 ), while no significant difference of aldosterone to cortisol ratio after ACTH stimulation between those with simple-PA (mean value: approximately 1.6) and CPA/PA was observed (8). It is noteworthy that both groups of simple-CPA and CPA/PA included both overt CS and SCS in the analysis (8). More recently, a recommendation has been made to perform screening test using ACTH loading to calculate the aldosterone to cortisol ratio after ACTH stimulation for all the patients with suspicion of CPA (overt CS or SCS with adrenal tumor), also suggesting a cut-off of $>0.85$ for subsequent AVS to detect complication of PA (31).

Upon AVS, the aldosterone level obtained from the right adrenal vein was $585 \mathrm{ng} / \mathrm{dL}$ at baseline. This finding rendered the possibility of hyperaldosteronism in the right adrenal gland as doubtful. However, the level of aldosterone after ACTH loading was $1,123 \mathrm{ng} / \mathrm{dL}$, which did not reach the criteria for PA of the JES guideline (9). Furthermore, the postoperative progress and ARR level $(=4.2)$ suggested that the remaining right adrenal gland functioned normally.

We reported herein a case originally diagnosed as overt CS and later as complicated with PA, with an aldosterone to cortisol ratio after ACTH stimulation (=1.19) meeting the proposed cut-off criteria of 0.85 . Our opinion is that not only absolute values of aldosterone to cortisol ratio after ACTH stimulation but also relative changes of ACR and/or PAC levels before and after ACTH stimulation should be taken into account when considering concurrent PA, especially in patients with overt CS with very low levels of ACTH. Further study, however, will be needed to establish 


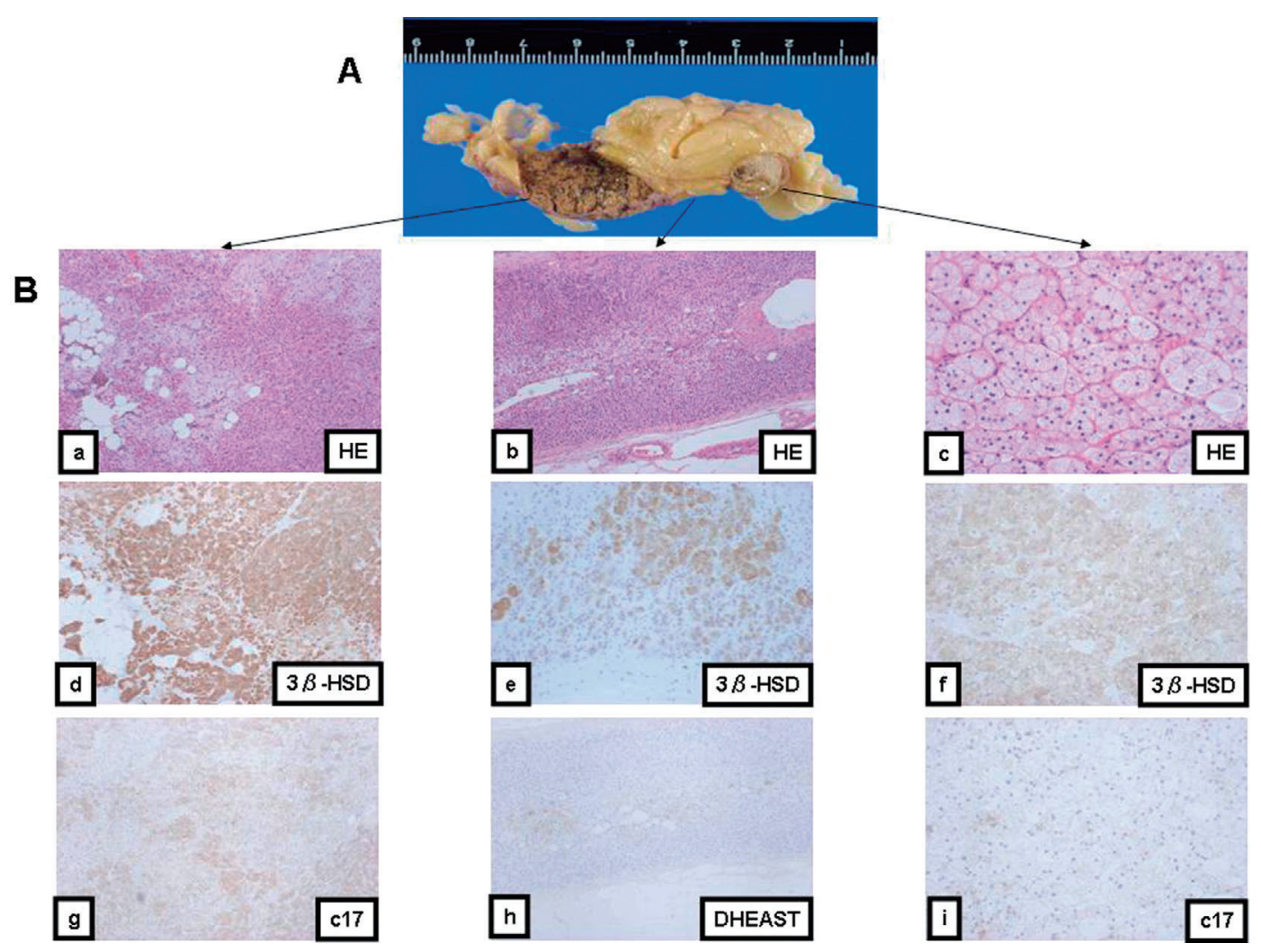

Figure 2. Pathological analysis of the surgically removed left adrenal gland: (A) Macroscopic features of the cut surface of the left adrenal tumors. The larger adrenal lesion appeared brown in color and the smaller one appeared golden yellow in color. Immunohistochemical analysis: (B) Hematoxylin and Eosin staining (a, b, c), 3 $\beta$-HSD immunohistochemistry (d, e, f), c17 immunohistochemistry (g, i), and DHEAST immunohistochemistry (h), a, d and g: the larger adrenocortical adenoma, $b$, e and $h$ : non-neoplastic adrenal and $c$, $f$ and $i$ : the smaller adrenocortical adenoma.

Table 3. Results of Adrenal Venous Sampling

\begin{tabular}{lcccccc}
\hline & \multicolumn{3}{c}{ Baseline } & \multicolumn{3}{c}{ ACTH 30min } \\
\hline & PAC & Cortisol & PAC/Cortisol & $\begin{array}{c}\text { PAC } \\
(\mathrm{ng} / \mathrm{dL})\end{array}$ & $\begin{array}{c}\text { Cortisol } \\
(\mu \mathrm{g} / \mathrm{dL})\end{array}$ & PAC/Cortisol \\
\hline (1) IVC & $<1.0$ & 16.2 & $<0.06$ & 17.7 & 27.6 & 0.64 \\
(2) It adrenal vein & 7 & 257 & 0.03 & 4140 & 969 & 4.27 \\
(3) rt adrenal vein & 585 & 8.4 & 10.01 & 1122 & 71.0 & 15.80 \\
\hline
\end{tabular}

the solid criteria using ACTH loading test to detect patients with hyperaldosteronism, which may be hidden in overt adrenal CS.

It is also necessary to seek a new method to judge the cannulation success at AVS, because the current method using cortisol concentrations in adrenal veins cannot be the gold standard due to variable ACTH levels which regulate normal adrenal zona fasciculata in overt or subclinical adrenal CS. Recently a method utilizing chromogranin measurement has been studied for the substitution of selectivity index (SI) using cortisol in AVS (32). Although the sensitivity of chromogranin-SI was reportedly lower than that of cortisol-SI for patients with simple-PA, it may be available as one of the substituting standards in assessment or inter- pretation of AVS results for patients with PA/CPA.

In conclusion, a case with cortisol producing adrenal adenoma was described. The patient was also affected with APA but hyperaldosteronism had been masked probably because of ACTH suppression induced by CS. ACTH loading test was effective to detect latent hyperaldosteronism, and two separate adenomas in the left adrenal gland were successfully resected with complete cure of the two disorders. As the comorbidity of the two disorders seems present more frequently than generally recognized, careful pre-treatment diagnosis is necessary, especially to avoid post-surgical exacerbation of the latent hyperaldosteronism.

The authors state that they have no Conflict of Interest (COI). 
D.K. and N.M. contributed equally to this work.

\section{References}

1. Gordon RD, Stowasser M, Tunny TJ, Klemm SA, Rutherford JC. High incidence of primary aldosteronism in 199 patients referred with hypertension. Clin Exp Pharmacol Physiol 21: 315-318, 1994.

2. Komiya I, Yamada T, Takasu N, et al. An abnormal sodium metabolism in Japanese patients with essential hypertension judged by serum sodium distribution, renal function and the renninaldosterone system. J Hypertens 15: 65-72, 1997.

3. Loh KC, Koay ES, Khaw MC, Emmanuel SC, Young WF Jr. Prevalence of primary aldosteronism among Asian hypertensive patients in Singapore. J Clin Endocrinol Metab 85: 2854-2859, 2000.

4. Nomura K, Kusakabe K, Maki M, Ito Y, Aiba M, Demura H. Iodomethylnorcholesterol uptake in an aldosteronoma shown by dexamethasone-suppression scintigraphy: relationship to adenoma size and functional activity. J Clin Endocrinol Metab 71: 825-830, 1990.

5. Magill SB, Raff H, Shaker JL, et al. Comparison of adrenal vein sampling and computed tomography in the differentiation of primary aldosteronism. J Clin Endocrinol Metab 86: 1066-1071, 2001.

6. Rossi GP, Sacchetto A, Chiesura-Corona M, et al. Identification of the etiology of primary aldosteronism with adrenal vein sampling in patients with equivocal computed tomography and magnetic resonance findings: results in 104 consecutive cases. J Clin Endocrinol Metab 86: 1083-1090, 2001.

7. Omura M, Nishikawa T. Diagnostic efficacy of adrenal vein sampling. Nippon Naika Gakkai Zasshi 95: 695-701, 2006 (in Japanese).

8. Omura M, Nishikawa T. Clinical Manual of the Treatment for Cushing Syndrome. Shindan to Chiryosha Co., Ltd., Tokyo, 2009: 56-57 (in Japanese).

9. Folia Endocrinologica Japonica. 86(Suppl): 2010 (in Japanese).

10. Adachi J, Hirai Y, Terui K, et al. A report of 7 cases of adrenal tumors secreting both cortisol and aldosterone. Intern Med 42: 714-718, 2003.

11. Sasano H. Localization of steroidogenic enzymes in adrenal cortex and its disorders. Endocr J 41: 471-482, 1994.

12. Späth M, Korovkin S, Antke C, Anlauf M, Willenberg HS Aldosterone- and cortisol-co-secreting adrenal tumors: the lost subtype of primary aldosteronism. Eur J Endocrinol 164: 447-455, 2011.

13. Nakajima Y, Yamada M, Taguchi R, et al. Cardiovascular complications of patients with aldosteronism associated with autonomous cortisol secretion. J Clin Endocrin Metab 96: 2512-2518, 2011.

14. Nagae A, Murakami E, Hiwada K, Kubota O, Takada Y, Ohmori T. Primary aldosteronism with cortisol overproduction from bilateral multiple adrenal adenomas. Jpn J Med 30: 26-31, 1991.

15. Honda T, Nakamura $T$, Saito $Y$, Ohyama $Y$, Sumino $H$, Kurabayashi M. Combined primary aldosteronism and preclinical Cushing's syndrome: an unusual case presentation of adrenal ade- noma. Hypertens Res 24: 723-726, 2001.

16. Takeno R, Iguchi M, Kudo T, et al. J Jpn Endocr Soc 79: 103106, 2003 (in Japanese).

17. Sugawara A, Takeuchi K, Suzuki T, Itoi K, Sasano H, Ito S. A case of aldosterone-producing adrenocortical adenoma associated with a probable post-operative adrenal crisis: histopathological analyses of the adrenal gland. Hypertens Res 26: 663-668, 2003.

18. Okura T, Miyoshi K, Watanabe S, et al. Coexistence of three distinct adrenal tumors in the same adrenal gland in a patient with primary aldosteronism and preclinical Cushing's syndrome. Clin Exp Nephrol 10: 127-130, 2006.

19. Oki K, Yamane K, Sakashita Y, et al. Primary aldosteronism and hypercortisolism due to bilateral functioning adrenocortical adenomas. Clin Exp Nephrol 12: 382-387, 2008.

20. Onoda N, Ishikawa T, Nishio K, et al. Cushing's syndrome by left adrenocortical adenoma synchronously associated with primary aldosteronism by right adrenocortical adenoma: report of a case. Endocr J 56: 495-502, 2009.

21. Imai $T$, Seo $H$, Murata $Y$, et al. Dexamethasone-nonsuppressible cortisol in two cases with aldosterone-producing adenoma. J Clin Endocrinol Metab 72: 575-581, 1991.

22. Baert D, Nobels F, Van Crombrugge P. Combined Conn's and Cushing's syndrome: an unusual presentation of adrenal adenoma. Acta Clin Belg 50: 310-313, 1995.

23. Yamada Y, Omura M, Sasano H, Kadota Y, Nishikawa T, Sekihara H. Clinical Endocrinology (Hormone to Rinsho). 52: 141-150, 2004 (in Japanese).

24. Matuo Y, Sugano K, Tani Y, et al. Clinical Endocrinology (Hormone to Rinsho). 55: 169-174, 2007 (in Japanese).

25. Saito T, Ikoma A, Saito T, et al. Possibly simultaneous primary aldosteronism and preclinical Cushing's syndrome in a patient with double adenomas of right adrenal gland. Endocr J 54: 287-293, 2007.

26. Tachiki M, Ozaki Y, Tnanabe A, Isozaki O, Takano K. J Jpn Endocr Soc (Nippon Naibunpitsu Gakkai Zasshi) 83: 233-235, 2007 (in Japanese).

27. Morimoto R, Kudo M, Murakami O, et al. Difficult-to-control hypertension due to bilateral aldosterone-producing adrenocortical microadenomas associated with a cortisol-producing adrenal macroadenoma. J Hum Hypertens 25: 114-121, 2011.

28. Murakami H, Arihara $Y$, Sato F, et al. Clinical Endocrinology (Hormone to Rinsho). 47: 210-216, 1999 (in Japanese).

29. Omura M, Hashimoto S, Sasano H, Nishikawa T. J Jpn Endocr Soc (Nippon Naibunpitsu Gakkai Zasshi) 83: 29-32, 2007 in Japanese.

30. Hiraishi K, Yoshimoto T, Tsuchiya K, et al. Clinicopathological features of primary aldosteronism associated with subclinical Cushing's syndrome. Endocr J 58: 543-551, 2011.

31. Omura M, Makita K, Matui S, et al. Folia Endocrinologica Japonica. 87(Suppl): 49-52, 2011 (in Japanese).

32. Seccia TM, Miotto D, De Toni R, et al. Chromogranin a measurement for assessing the selectivity of adrenal venous sampling in primary aldosteronism. J Clin Endocrinol Metab 96: 825-829, 2011

(C) 2012 The Japanese Society of Internal Medicine

http://www.naika.or.jp/imindex.html 